\title{
Do Lumpectomy Cavity Shaved Margins Really Not Impact Re-excision Rates in Breast Cancer?
}

\author{
Alexandre Bricou ${ }^{1}$, Rita Sakr $^{2}$, and Emmanuel Barranger ${ }^{3}$ \\ ${ }^{1}$ Department of Gynecology, Jean Verdier Hospital, Paris Seine Saint Denis University, AP-HP, Bondy, France; \\ ${ }^{2}$ Department of Gynecology, Tenon Hospital, Pierre et Marie Curie University, AP-HP, Paris, France; ${ }^{3}$ Department of \\ Surgery, Antoine Lacassagne Cancer Center, Nice, France
}

\section{TO THE EDITORS}

We read with interest the report by Coopey et al. entitled "Lumpectomy cavity shaved margins do not impact reexcision rates in breast cancer patients". ${ }^{1}$ Their conclusion was that cavity shaved margins (CSMs) allowed a decrease in the overall volume of excised breast tissue with no increase in the locoregional recurrence rate, a finding that appears to be of great value. They also concluded that CSMs did not decrease re-excision. We would like to comment this conclusion. The CSMs can harbor foci of carcinoma in $8-10 \%$ of patients, whereas lumpectomy margins were all free of carcinoma. ${ }^{2}$ In the majorite majority of these cases, re-excision or mastectomy was needed after the CSM examination, especially when the CSMs were not oriented, thus the excision margins were not correctly determined. Even if CSMs are positive, reexcision can sometimes be avoided when CSMs are welloriented with correct security margins. This proves the importance of orienting all CSMs, even if they are thin. This attitude, in parallel with histological per operative analysis (HPOA) of the lumpectomy, may reduce re-excision rates. ${ }^{3}$ HPOA permits adaptation of the volume of CSM. In this report, neither the rate of oriented cavity margins nor the rate of positive CSMs or thin CSMs were mentioned; the thin CSMs may not influence the potential benefit on re-excision. Mastectomies for extensive disease in the different groups were not reported. The rate of nonpalpable lesions that require preoperative localization may

(C) Society of Surgical Oncology 2017

First Received: 12 October 2017;

Published Online: 24 October 2017

A. Bricou

e-mail: alexandre.bricou@aphp.fr influence the volume of excised breast tissue; however, this data is also missing. Extensive ductal carcinoma in situ with a high rate of non in sano is more frequent in the group with CSMs and can change the rate of re-excision. The main goal of CSMs is to perform a smaller lumpectomy with security margins, which could be well-analyzed by pathologists. Several studies have retrospectively compared the influence of CSMs on further surgical management by comparing the therapeutic options that would have been taken with lumpectomy alone, with that taken after the results of CSM examination. All concluded that CSMs would lead to the avoidance of re-excision in $20-50 \%$ of cases. ${ }^{2}$ The most efficient criteria will be the local recurrence rates at 5 and 10 years. We strongly support the fact that a systematic analysis of CSMs in breast-conservation surgery allows better assessment of the tumor's margins. With regard to survival, cavity status seems to be more significant than margin status. ${ }^{4}$

\section{REFERENCES}

1. Coopey SB, Buckley JM, Smith BL, et al. Lumpectomy cavity shaved margins do not impact re-excision rates in breast cancer patients. Ann. Surg. Oncol. 2011;18(11):3036-40.

2. Tengher-Barna I, Antoine M, Bricou A, Ziol M. Cavity margins examination in breast conserving therapy. Diagn. Histopathol. 2011;17:232-37.

3. Héquet D, Bricou A, Delpech Y, Barranger E. Surgical management modifications following systematic additional shaving of cavity margins in breast-conservation treatment. Ann. Surg. Oncol. 2011;18(1):114-18.

4. Hewes JC, Imkampe A, Haji A, Bates T. Importance of routine cavity sampling in breast conservation surgery. Br. J. Surg. 2009;96(1):47-53. 